\title{
Screening of minor psychiatric disorders and burnout among a sample of medical students in St. Petersburg, Russia: a descriptive study
}

Egor Chumakov ${ }^{1,2^{*}}$ (D, Nataliia Petrova ${ }^{1}$, Tamila Mamatkhodjaeva ${ }^{1}$, Antonio Ventriglio ${ }^{3}$, Dinesh Bhugra ${ }^{4}$ and Andrew Molodynski $i^{5,6}$

\begin{abstract}
Background: Despite the general interest of researchers around the world, there are few studies on the psychological wellbeing and burnout among medical students in Russia. The aim of this study was to perform screening for minor psychiatric disorders, burnout, problematic alcohol use, and quantify the psychological issues and stress among a sample of medical students in St. Petersburg, Russia.

Results: According to the GHQ-12, screening for minor mental disorders was positive in 140 students (85\%). Screening for burnout using the OLBI showed positive results in 121 (73\%) students for disengagement and 132 (80\%) students for exhaustion. Screening with the CAGE tool identified a risk of alcohol consumption in 33 students (20\%). Most students reported academic studies as the main source of stress in their life $(n=147 ; 89.1 \%)$.

Conclusions: This study identified very high levels of stress, burnout, risk of minor mental disorders, and problematic alcohol use among medical students in St. Petersburg, Russia. These findings suggest more attention is needed to the poor mental wellbeing and health in medical students in Russia.
\end{abstract}

Keywords: Medical students, Wellbeing, Professional burnout, Alcohol abuse, Stress

\section{Background}

The psychological adaptation of medical students and young doctors is of interest in many countries [1-6]. Research consistently shows a high prevalence of mental disorders and psychological stress among medical students [3, 7-9], significantly higher than in the general population [10, 11]. The incidence of depression and anxiety in a sample of Russian medical students was 4 and 6 times higher, respectively, than in students of

\footnotetext{
* Correspondence: chumakovegor@gmail.com

${ }^{1}$ St. Petersburg State University, 7/9 Universitetskaya Emb, Saint Petersburg, Russian Federation 199034

${ }^{2}$ St. Petersburg Psychiatric Hospital № 1 named after P.P. Kaschenko, 12 Kanonerskaya Street, Saint Petersburg, Russian Federation, 190121

Saint-Petersburg, Russia

Full list of author information is available at the end of the article
}

other disciplines [12]. Also, of particular concern is the increasing prevalence of suicidal ideation in medical students $[6,9,13,14]$.

Medical students report pressure from their professional environment and academic studies are the main source of stress $[3,5,15]$. These stressful conditions may lead to high burnout rates [16-21]. Other sources of stress include psychosocial issues and environmental stressors [15, 22], financial problems, housing, and relationships [3]. The consequences of psychological adaptation difficulties in students are also shown in social life, leading to substance misuse $[12,23]$ and reduced learning achievements [24, 25].

The medical-training period is recognized as a crucial phase for the onset of mental disorders among doctors [10]. It is therefore relevant to study this phase as well as 
to develop prevention and psychohygiene strategies. Medical-training currently requires significant emotional and financial investment, so it is critical that faculty and managers provide help and support to these future physicians [9]. Mental health promotion for medical students calls for evidence-based interventions and psychosocial support [4]. Researchers strongly recommend widespread screening for symptoms of burnout and mental disorders in medical students in order to provide timely and appropriate interventions [6]. Despite the general interest of researchers around the world, there are few studies on psychological wellbeing and burnout among medical students in Russia [12, 22].

The aim of this study was to perform screening for minor psychiatric disorders, burnout, problematic alcohol use, and quantify the psychological issues and stress among a sample of medical students in St. Petersburg, Russia.

\section{Methods \\ Procedure}

An anonymous online survey of medical students of St. Petersburg State University Medical Faculty was conducted in May-June 2020. The research employed the online platform questionpro.com. The invitation to participate in the research has been sent through the mailing list of students' council of the faculty and was also published in social networks groups for students. Reminders were sent at second and fourth week from the launch of the survey. Each student could complete the survey just one time and participation was anonymous and voluntary. Data were password-protected and answers were confidentially treated. Individual respondents could not be identified. The authors assert that all procedures contributing to this work comply with the ethical standards of the relevant national and institutional committee on human experimentation with the Helsinki Declaration of 1975, as revised in 2008. The study protocol was approved by the ethics committee of the St. Petersburg State University.

\section{Participants}

A total of 174 students completed the survey (response rate $43.2 \%)$. We calculated that the sample size 161 or more respondents are needed to have a confidence level of $95 \%$ that the real value is within $\pm 6 \%$ of the surveyed value (the margin of error is 0.06). Since we expected that there might be difficulties in recruiting respondents for the online survey, we took into account a possible minor downward deviation from the common target values. Only nine students did not answer all the key questions in the survey, and these students were excluded from the final analysis. The final sample included
165 respondents who answered all the key questions of this survey.

\section{Measures}

The survey was conducted in Russian and collected basic demographic information and structured questionnaires with proposed answers and the item "other" in those cases when the questions were not quantitative. Choosing "other" allowed respondents to provide their personalized answer. The first part of the survey consisted of a structured questionnaire that included questions about students' mental health and psychological wellbeing before and during their studies at the university, including any history of mental health problems, use of prescription (and non-prescription) medications, drug and alcohol use, main sources of stress experienced by students, etc. The full text of the questionnaire is available from the first author upon request.

Minor psychiatric disorders were identified through the Short General Health Questionnaire (GHQ-12) [26]; Oldenburg Burnout Inventory (OLBI) was used to identify burnout [27], while problem alcohol use was identified using the CAGE (cut-down; annoyed; guilty; eyeopener) questionnaire [28]. For the GHQ-12, the bimodal GHQ scoring method (0-0-1-1) was used, and a score of two was considered as the cut-off to identify cases, based on standardized and validated results [29]. For the OLBI, burnout was detected by combining the mean score of 2.25 for exhaustion and 2.10 for disengagement [30]. Finally, for the CAGE questionnaire, a score of $\geq 2$ was considered as the cut-off for problem drinking [31]. All ratings were previously translated and adapted in Russian: GHQ-12 Cronbach's $\alpha=0.751$ [32]; OLBI disengagement Cronbach's $\alpha=0.652$ [33]; OLBI Exhaustion Cronbach's $\alpha=0.838$ [33]; CAGE Cronbach's $\alpha=0.71$ [34].

\section{Statistical analysis}

Data were entered and analyzed using IBM SPSS Statistics (Version 24). Research data are presented as the arithmetic mean and standard deviation $(M \pm S D)$. We used chi-square $\left(\chi^{2}\right)$ tests for categorical variables and to compare proportions. The correlation between the indices was studied by means of a linear correlation analysis, the Pearson test. Correlation coefficient $\left(r_{\mathrm{s}}\right)$ from 0.3 to 0.7 means a moderate positive; negative $r_{\mathrm{s}}$ corresponds to inverse correlation.

\section{Results}

Sociodemographic characteristics of respondents are shown in Table 1. No students selected the item "others" in the question about gender. Most participants were in the 5th year of study, which may reflect the fact that these students were trained in "psychiatry, medical 
Table 1 Sociodemographic characteristics of 165 surveyed students

\begin{tabular}{ll}
\hline Demographics & Number of students (\%) \\
\hline Gender & $132(80.0 \%)$ \\
Female & $33(20.0 \%)$ \\
Male & \\
Year of study & $28(17.0 \%)$ \\
1st & $24(14.5 \%)$ \\
2nd & $29(17.6 \%)$ \\
3rd & $19(11.5 \%)$ \\
4th & $39(23.6 \%)$ \\
5th & $26(15.8 \%)$ \\
6th &
\end{tabular}

psychology". Information regarding the educational achievements of parents was obtained from each student, with $1(0.6 \%)$ indicating high school or below, 8 (4.8\%) indicating GCSE (General Certificate of Secondary Education), 13 (7.9\%) indicating A-Level or equivalent, 117 (70.9\%) indicating undergraduate, and 26 (15.8\%) indicating postgraduate education.

Assessing students' mental health in the period before entering the university, $27(16.4 \%)$ reported that during that period they had visited a general practitioner, psychologist, psychiatrist, psychotherapist, or other specialist in the field of mental health for reasons related to psychological issues (including reduced mood, anxiety, eating disorders, or obsessions). Ten individuals (6.1\%) reported they had been diagnosed with mental health disorders before entering medical school, of which four students (2.4\%) received an attention deficit hyperactivity disorder (ADHD) or autism spectrum disorder diagnosis. $10.3 \%$ of students $(n=17)$ also indicated that they had been prescribed medications for a mental disorder (including depression, anxiety, psychosis, ADHD) during that period.

Twenty-five students (15.2\%) reported they had been diagnosed with a mental disorder while at university whereas 18 students (10.9\%) indicated that they were having care by a general practitioner, psychologist, psychiatrist, psychotherapist, or other mental health professional during their participation in the study. The same number of students $(n=18 ; 10.9 \%)$ reported they were on a maintenance treatment during the survey.

Students reported academic studies as the main source of stress in their life $(\mathrm{n}=147 ; 89.1 \%)$. Other sources of stress included social relationships (intimate or family; $\mathrm{n}$ $=84 ; 50.9 \%)$, financial wellbeing $(\mathrm{n}=63 ; 38.2 \%)$, work $(\mathrm{n}$ $=53 ; 32.1 \%)$, and housing problems $(\mathrm{n}=34 ; 20.6 \%)$. Ten students $(6.1 \%)$ also identified other sources of stress such as low self-esteem, social problems, anxiety about their own health or health of their relatives, career after graduation, and existential issues. Most respondents reported having two $(n=60 ; 36.4 \%)$ or three $(n=43$; $26.1 \%)$ main sources of stress. One source of stress was reported by $30(18.2 \%)$ respondents, while four and five sources were reported by $15(9.1 \%)$ and $10(6.1 \%)$ students, respectively. Only seven people (4.2\%) did not report any stress in their lives.

Screening with the CAGE tool identified alcohol problems in 33 students (20.0\%). 23.6\% of students $(n=39)$ had experience with illegal drugs, including cannabis (n $=37 ; 22.4 \%)$, ecstasy $(\mathrm{n}=10 ; 6.1 \%)$, amphetamines $(\mathrm{n}=$ $7 ; 4.2 \%)$, cocaine $(\mathrm{n}=2 ; 1.2 \%)$, opiates $(\mathrm{n}=2 ; 1.2 \%)$, and others $(\mathrm{n}=8 ; 4.8 \%)$. The number of students who were worried about psychoactive substance use was very low ( $\mathrm{n}=5 ; 3.6 \%)$. Only $4.8 \%(\mathrm{n}=8)$ of respondents indicated that others expressed concerns about their own substance use.

More than one-third of respondents $(n=63 ; 38.3 \%)$ reported that they had taken a psychoactive substance in the last year before the course in order to improve their concentration or academic performance (excluding caffeine or other energy drinks). Forty-five students (27.3\%) reported taking non-prescription substance or medications outside their intended use to feel better or uplift their mood.

According to the GHQ-12, 140 students (84.8\%) had a total score of 2 or higher, indicating a high risk of minor mental disorders in the sample. The mean value of the total GHQ-12 score in the study group was $5.05 \pm 3.04$. The screening for burnout using the OLBI showed positive scores in $121(73.3 \%)$ students for disengagement and $132(80.0 \%)$ students for exhaustion. A positive statistically significant correlation has been found between the overall GHQ-12 score and OLBI disengagement and exhaustion scores (Table 2), as well as between individual OLBI scores. The correlation between training course and OLBI disengagement was less than moderate. No differences were found in the frequency of positive screening of the survey's techniques when dividing respondents by gender (Table 3 ).

\section{Discussion}

This survey collected further and relevant evidence regarding the wellbeing and health issues of medical students in St. Petersburg, Russia. Young people's health has a potential impact on future population health and global economic development unless timely and effective strategies are adopted [35].

Some differences in the frequency of mental disorders were found in respondents who reported being diagnosed before entering university $(6.1 \%)$ or during their own training (15.2\%), while GHQ-12 screening for general (non-psychotic) mental health problems was positive in $84.8 \%$ of respondents. In a previous study 
Table $\mathbf{2}$ Correlations between the studied values

\begin{tabular}{lllllll}
\hline & & Year of study & CAGE & GHQ-12 & Disegagement & Exhaustion \\
\hline Year of study & $\mathrm{r}$ & & -.078 & -.082 & $.192^{*}$ & .139 \\
& $\mathrm{p}$ & & .321 & .296 & .014 & .076 \\
CAGE & $\mathrm{r}$ & -.078 & & .083 & $.171^{*}$ & .143 \\
& $\mathrm{p}$ & .321 & & .289 & .028 & .066 \\
GHQ12 & $\mathrm{r}$ & -.082 & .083 & & $.442^{* *}$ & $.516^{* *}$ \\
& $\mathrm{p}$ & .296 & .289 & & .000 & .000 \\
Disegagement & $\mathrm{r}$ & $.192^{*}$ & $.171^{*}$ & $.442^{* *}$ & $.750^{* *}$ \\
& $\mathrm{p}$ & .014 & .028 & .000 & .000 \\
Exhaustion & $\mathrm{r}$ & .139 & .143 & $.516^{* *}$ & $.750^{* *}$ & .000 \\
\end{tabular}

$r$ Pearson coefficient, $p$ statistical significance

${ }^{*} \mathrm{p}<0.05$

$* * p<0.001$

conducted in Russia, clinically significant symptoms of social phobia and generalized anxiety were found in $16 \%$ of medical students, while symptoms of depression (according to the depression anxiety stress scale-21) were observed in $34 \%$ of medical students [12]. The frequency (27.3\%) of use of non-prescription substance or medications outside prescription over the past year is alarming, indicating a high probability of self-treatment in the study group. Although a screening survey is not sufficient to make a diagnosis, data obtained clearly indicated a high probability of common mental disorders in the study sample.

Academic stress and the pressure of the professional environment were rated as the leading global sources of stress in medical students $[3,5,15]$. This was confirmed in our survey, where academic studies were the most frequently cited source of stress ( $89 \%$ of respondents). Further evidence of the importance of academic stress among our respondents was the widespread taking of medications aimed at increasing concentration or improving academic performance (38.3\%) over the past year. In another study from Russia, 26.0\%, 69.1\%, and $4.9 \%$ medical students reported low, moderate, and high perceived stress respectively [22]. According to the literature, perceived stress in medical students was higher among older groups and final year medical students [15], but this was not confirmed in our study.

There is no doubt that study or work places affect our mental health and wellbeing [1]. The burnout of health workers is an important contributory factor in medical errors and reduced quality of medical care [7]. Thus, it is very important to focus on burnout prevention during the training period. Our study found high frequencies of both disengagement (73.3\%) and exhaustion (80.0\%). The relationship found in the study between the frequency of burnout symptoms and the GHQ-12 score appears to confirm the potential link between burnout and the risk of developing mental disorders, particularly depression [36]. These indicators are discouraging and should be treated as a call for direct action to improve the psychological wellbeing of students. It should be noted, however, that the reported frequency of emotional burnout symptoms among Russian medical students is lower than in many other countries [3]. Further studies are required to assess the possible causes of these cultural differences, as well as the socio-cultural factors potentially associated with them.

One in five students has shown signs of alcohol problems using the CAGE questionnaire, significantly higher than in other countries [3]. Our data are consistent with

Table 3 Rates of positive GHQ-12, OLBI disengagement, OLBI exhaustion, and CAGE screening by gender of respondents

\begin{tabular}{llll}
\hline $\begin{array}{l}\text { Screening } \\
\text { techniques }\end{array}$ & Female students $(\mathbf{n}=\mathbf{1 3 2})$ & $\begin{array}{l}\text { Male students } \\
\mathbf{( n = 3 3 )} \\
\mathbf{n}(\%)\end{array}$ & $\chi^{2}(\mathbf{d f}), \boldsymbol{p}$ \\
\hline GHQ-12 & $\mathbf{n}(\%)$ & $28(84.8 \%)$ & $x^{2}(1)=0, p=1.0$ \\
OLBI & $112(84.8 \%)$ & & $x^{2}(1)=1.98, p=0.159$ \\
Disegagement & & $21(63.6 \%)$ & $x^{2}(1)=1.36, p=0.24$ \\
Exhaustion & $100(75.8 \%)$ & $24(72.7 \%)$ & $x^{2}(1)=0.038, p=0.85$ \\
CAGE & $108(81.8 \%)$ & $7(21.2 \%)$ & \\
\hline
\end{tabular}


literature from Russia. In fact, in a previous study on alcohol use, heavy drinking, and problem behavior among Russian Federation university students, heavy alcohol use was revealed in $20.4 \%$ of them [37]. Another study found that heavy drinking among university students in Russia was common for $37.1 \%$ of men and $39.6 \%$ of women [38], and those were the highest rates among 24 countries. Alcohol use was the leading risk factor for death among young people aged 15-19 and 20-24 in both 1990 and 2013 Global Burden of Disease Study reports [35]. However, a recent study showed a clear trend toward a decline in alcohol consumption among adolescents and young adults under 25 in Russia [39], which may explain the differences in frequencies between our and previous studies.

In order to determine potential risk groups for burnout, problematic alcohol use and risk of general (nonpsychotic) mental health problems, the results of the study were compared according to participants' gender. No statistically significant differences were found in the studied items. Moreover, no statistically significant correlation between the studied indicators and the students' course of study was obtained. The reason for this may be the relatively small sample in the study.

This study was conducted during the period of social restrictions imposed in St. Petersburg to combat the spreading of COVID-19. Although there was no official ban on leaving home, movement around the city and students' social contacts were significantly limited and all university classes were converted to remote learning. Not surprisingly, research in Russia over the past year has confirmed that during the COVID-19 pandemic lockdown has led to emotional disturbance, depression, irritability, insomnia, anger, and emotional exhaustion among other things [40, 41]. Young people have been particularly exposed to psychological stress during the period of social isolation in Russia [41]. Although we did not assess the direct association between the results of the study and the finding of respondents in selfisolation, the authors report that at the time of the study all students participating in the study were at least switched to distance learning and were subject to general instructions from the St. Petersburg and Russian governments with recommendations for self-isolation. These additional external factors may have affected the level of stress and burnout in the study sample, so it may be advisable to compare our findings with further studies after the end of pandemic.

In summary, this research sheds some light on the problem of psychological wellbeing and health of medical students in Russia. Academic schedules and load of medical students should be balanced to prevent educational stress, anxiety, and depression [12]. Administrative measures should focus on developing preventative strategies for stress management to improve students' psychological wellbeing [22]. We also hope that our study motivated the participating medical students to self-reflect and try to optimize their psychological state.

\section{Strengths and limitations}

The main strength of this research was the employment of reliable screening tools, extensively and internationally used as in some previous studies on the psychological wellbeing of medical students. Despite its originality, this study has some limitations.

It was based on an online survey which guaranteed confidentiality, but respondents were self-selected and theoretically it is possible that those who were experiencing problems may have been more likely to respond. Diagnoses of mental disorders are also self-reported and not clinically confirmed. The study was conducted during the COVID-19 pandemic quarantine measures and lockdown, which may have affected stress levels, burnout, and current mental health problems in the sample. Therefore, it would be useful to conduct the study in dynamics after the removal of all social restrictions. Also, it would have been interesting and useful to conduct a comparison with students from other disciplines such as psychology, social workers students, and dentistry students.

\section{Conclusion}

This study reported high levels of burnout, stress, problematic alcohol use, and risk of minor mental disorders in medical students in St. Petersburg, Russia. It may suggest more attention to the mental wellbeing and health in medical students in Russia. Also, these findings might suggest strategies to improve mental health, contrast stigma, and discrimination, and prevent mental disorders among medical students.

\section{Abbreviations \\ GHQ-12: Short General Health Questionnaire; OLBI: Oldenburg Burnout Inventory; CAGE: Cut-down, Annoyed, Guilty, Eye-opener; M: Mean; SD: Standard deviation; GCSE: General Certificate of Secondary Education; ADHD: Attention deficit hyperactivity disorder}

\section{Acknowledgements}

The authors would like to show their gratitude to all the study participants.

\section{Authors' contributions}

$E C, N P, A V, D B$, and $A M$ are involved in the conception and design of the study. EC, NP, and TM collected data and performed data analysis and interpretation. EC and NP wrote the manuscript. TM, AV, DB, and AM helped to evaluate and edit the manuscript. EC acted as the corresponding author. All authors read and approved the final manuscript.

\section{Funding}

This research did not receive any specific grant from funding agencies in the public, commercial, or not-for-profit sectors.

Availability of data and materials

The datasets used and/or analyzed during the current study are available from the corresponding author on reasonable request. 


\section{Declarations}

\section{Ethics approval and consent to participate}

Ethical approval for the study was granted by the ethics committee of the St. Petersburg University (reference number 02-200 dated 20 April 2020), in line with the principles of the Declaration of Helsinki. Online consent was obtained from the participants.

\section{Consent for publication}

Not applicable.

\section{Competing interests}

The authors declare that they have no competing interests.

\section{Author details}

'St. Petersburg State University, 7/9 Universitetskaya Emb, Saint Petersburg, Russian Federation 199034. ${ }^{2}$ St. Petersburg Psychiatric Hospital № 1 named after P.P. Kaschenko, 12 Kanonerskaya Street, Saint Petersburg, Russian Federation, 190121 Saint-Petersburg, Russia. ${ }^{3}$ Department of Clinical and Experimental Medicine, University of Foggia, Foggia, Italy. ${ }^{4}$ Institute of Psychiatry, King's College London, London, UK. ${ }^{5}$ Oxford Health NHS Foundation Trust, Oxford, UK. ${ }^{6}$ Oxford University, Oxford, UK.

\section{Received: 14 May 2021 Accepted: 20 June 2021}

\section{Published online: 26 August 2021}

\section{References}

1. Bhugra D, Sauerteig SO, Bland D, Lloyd-Kendall A, Wijesuriya J, Singh G, Kochhar A, Molodynski A, Ventriglio A (2019) A descriptive study of menta health and wellbeing of doctors and medical students in the UK. Int Rev Psychiatry 31(7-8):563-568. https://doi.org/10.1080/09540261.2019.1648621

2. Lucchetti G, Damiano RF, DiLalla LF, Lucchetti ALG, Moutinho ILD, da Silva EO, Dorsey JK (2018) Cross-cultural differences in mental health, quality of life, empathy, and burnout between US and Brazilian medical students. Acad Psychiatry 42(1):62-67. https://doi.org/10.1007/s40596-017-0777-2

3. Molodynski A, Lewis T, Kadhum M, Farrell SM, Lemtiri Chelieh M, Falcão De Almeida T, Masri R, Kar A, Volpe U, Moir F, Torales J, Castaldelli-Maia JM, Chau SWH, Wilkes C, Bhugra D (2020) Cultural variations in wellbeing, burnout and substance use amongst medical students in twelve countries. Int Rev Psychiatry 33(1-2):37-42. https://doi.org/10.1080/09540261.2020.173 8064

4. Pacheco JP, Giacomin HT, Tam WW, Ribeiro TB, Arab C, Bezerra IM, Pinasco GC (2017) Mental health problems among medical students in Brazil: a systematic review and meta-analysis. Braz J Psychiatry 39(4):369-378. https:// doi.org/10.1590/1516-4446-2017-2223

5. Ruzhenkova V, Ruzhenkov V, Lukyantseva I, Anisimova N (2018a) Academic stress and its effect on medical students' mental health status. Drug Invent Today 10:1171-1174

6. Zeng W, Chen R, Wang X, Zhang Q, Deng W (2019) Prevalence of mental health problems among medical students in China: a meta-analysis. Medicine (Baltimore) 98(18):e15337. https://doi.org/10.1097/MD. 0000000000015337

7. Alexandrova-Karamanova A, Todorova I, Montgomery A, Panagopoulou E, Costa P, Baban A, Davas A, Milosevic M, Mijakoski D (2016) Burnout and health behaviors in health professionals from seven European countries. Int Arch Occup Environ Health 89(7):1059-1075. https://doi.org/10.1007/s00420016-1143-5

8. Dyrbye LN, Thomas MR, Massie FS, Power DV, Eacker A, Harper W, Durning S, Moutier C, Szydlo DW, Novotny PJ, Sloan JA, Shanafelt TD (2008) Burnout and suicidal ideation among U.S. medical students. Ann Intern Med 149(5): 334-341. https://doi.org/10.7326/0003-4819-149-5-200809020-00008

9. Watson C, Ventriglio A, Bhugra D (2020) A narrative review of suicide and suicidal behavior in medical students. Indian J Psychiatry 62(3):250-256. https://doi.org/10.4103/psychiatry.IndianJPsychiatry_357_20

10. Dyrbye LN, West CP, Satele D, Boone S, Tan L, Sloan J, Shanafelt TD (2014) Burnout among U.S. medical students, residents, and early career physicians relative to the general U.S. population. Acad Med 89(3):443-451. https://doi. org/10.1097/ACM.0000000000000134

11. Moir F, Yielder J, Sanson J, Chen Y (2018) Depression in medical students: current insights. Adv Med Edu Prac 9:323-333. https://doi.org/10.2147/A MEP.S137384
12. Ruzhenkova V, Tarabaeva V, Ruzhenkov V, Lukyantseva I (2018b) Medical and psychological characteristics of the 1st year students of medical and pedagogical institutes and their features of educational adaptation. Drug Invent Today 10:3240-3246

13. Győrffy Z, Girasek E (2015) Mental health of physicians - nationwide representative study from Hungary. Ideggyógyászati Szemle 68(7-8):258269. https://doi.org/10.18071/isz.68.0258

14. Rotenstein LS, Ramos MA, Torre M, Segal JB, Peluso MJ, Guille C, Sen S, Mata DA (2016) Prevalence of depression, depressive symptoms, and suicidal ideation among medical students: a systematic review and metaanalysis. J Am Med Assoc 316(21):2214-2236. https://doi.org/10.1001/jama.2 016.17324

15. Anuradha R, Dutta R, Raja JD, Sivaprakasam P, Patil AB (2017) Stress and stressors among medical undergraduate students: a cross-sectional study in a private medical college in Tamil Nadu. Indian J Community Med 42(4): 222-225. https://doi.org/10.4103/ijcm.IJCM_287_16

16. Almeida T, Kadhum M, Farrell SM, Ventriglio A, Molodynski A (2019) A descriptive study of mental health and wellbeing among medical students in Portugal. Int Rev Psychiatry 31(7-8):574-578. https://doi.org/10.1080/0954 0261.2019.1675283

17. Castaldelli-Maia JM, Lewis T, Marques Dos Santos N, Picon F, Kadhum M, Farrell SM, Molodynski A, Ventriglio A (2019) Stressors, psychological distress, and mental health problems amongst Brazilian medical students. Int Rev Psychiatry 31(7-8):603-607. https://doi.org/10.1080/09540261.2019.1669335

18. Lemtiri Chelieh M, Kadhum M, Lewis T, Molodynski A, Abouqal R, Belayachi J, Bhugra D (2019) Mental health and wellbeing among Moroccan medical students: a descriptive study. Int Rev Psychiatry 31(7-8):608-612. https://doi. org/10.1080/09540261.2019.1675276

19. Farrell SM, Kadhum M, Lewis T, Singh G, Penzenstadler L, Molodynski A (2019) Wellbeing and burnout amongst medical students in England. Int Rev Psychiatry 31(7-8):579-583. https://doi.org/10.1080/09540261.2019.1 675960

20. Masri R, Kadhum M, Farrell SM, Khamees A, Al-Taiar H, Molodynski A (2019) Wellbeing and mental health amongst medical students in Jordan: a descriptive study. Int Rev Psychiatry 31(7-8):619-625. https://doi.org/10.1 080/09540261.2019.1670402

21. Wilkes C, Lewis T, Brager N, Bulloch A, MacMaster F, Paget M, Holm J, Farrell SM, Ventriglio A (2019) Wellbeing and mental health amongst medical students in Canada. Int Rev Psychiatry 31(7-8):584-587. https://doi.org/10.1 080/09540261.2019.1675927

22. Drachev S, Stangvaltaite-Mouhat $\mathrm{L}$, Bolstad NL, Johnsen JA, Yushmanova T, Trovik T (2020) Perceived stress and associated factors in Russian medical and dental students: a cross-sectional study in north-west Russia. Int J Environ Res Public Health 17(15):5390. https://doi.org/10.3390/ijerph171553 90

23. Newbury-Birch D, Walshaw D, Kamali F (2001) Drink and drugs: from medical students to doctors. Drug Alcohol Depend 64(3):265-270. https:// doi.org/10.1016/s0376-8716(01)00128-4

24. Rennie SC, Rudland JR (2003) Differences in medical students' attitudes to academic misconduct and reported behaviour across the years--a questionnaire study. J Med Ethics 29(2):97-102. https://doi.org/10.1136/ jme.29.2.97

25. Varzin SA, Piskun OE, Petrova NN (2014) Comparative assessment of personality-mental characteristics and mental state of undergraduates. Teoriya i Praktika Fizicheskoy Kultury 7:20-22

26. Goldberg DP, Gater R, Sartorius N, Ustun TB, Piccinelli M, Gureje O, Rutter C (1997) The validity of two versions of the GHQ in the WHO study of mental illness in general health care. Psychol Med 27(1):191-197. https://doi.org/1 $0.1017 /$ s0033291796004242

27. Reis D, Xanthopoulou D, Tsaousis I (2015) Measuring job and academic burnout with the Oldenburg Burnout Inventory (OLBI): Factorial invariance across samples and countries. Burn Res 2(1):8-18. https://doi.org/10.1016/j. burn.2014.11.001

28. Saitz R, Lepore MF, Sullivan LM, Amaro H, Samet JH (1999) Alcohol abuse and dependence in Latinos living in the United States: validation of the CAGE (4M) questions. Arch Intern Med 159(7):718-724. https://doi.org/10.1 001/archinte.159.7.718

29. Kim YJ, Cho MJ, Park S, Hong JP, Sohn JH, Bae JN, Jeon HJ, Chang SM, Lee HW, Park J (2013) The 12-item general health questionnaire as an effective mental health screening tool for general korean adult population. Psychiatry Investig 10(4):352-358. https://doi.org/10.4306/pi.2013.10.4.352 
30. Peterson U, Demerouti E, Bergström G, Samuelsson M, Asberg M, Nygren A (2008) Burnout and physical and mental health among Swedish healthcare workers. J Adv Nurs 62(1):84-95. https://doi.org/10.1111/j.1365-2648.2007.04 580. $\mathrm{x}$

31. Masur J, Monteiro MG (1983) Validation of the "CAGE" alcoholism screening test in a Brazilian psychiatric inpatient hospital setting. Braz I Med Biol Res 16(3):215-218

32. Glendenning A, Yu P, Selezneva E (2017) Mental health of modern teenagers (based on sociological survey in the republic of altai). Ural Hist $J$ 1:83-91

33. Smirnova A (2017) The Oldenburg Burnout Inventory: diagnostics of state of mind's change of the employ on a continuum: work engagement professional burnout. Philosophy Psychology Pedagogy 17(2):211-218 https://doi.org/10.18500/1819-7671-2017-17-2-211-218

34. Barinova A, Plavinski S, Yu Y, Polovinkina T (2013) Screening for harmful and hazardous alcohol consumption among detainees in criminal justice system. Herald of North-Western State Medical University named after I.I. Mechnikov 5:84-91

35. Mokdad AH, Forouzanfar MH, Daoud F, Mokdad AA, El Bcheraoui C, MoradiLakeh M, Kyu HH, Barber RM, Wagner J, Cercy K, Kravitz H, Coggeshall M, Chew A, O'Rourke KF, Steiner C, Tuffaha M, Charara R, Al-Ghamdi EA, Adi Y, Afifi RA, Alahmadi H, AlBuhairan F, Allen N, AlMazroa M, Al-Nehmi AA AlRayess Z, Arora M, Azzopardi P, Barroso C, Basulaiman M, Bhutta ZA, Bonell C, Breinbauer C, Degenhardt L, Denno D, Fang J, Fatusi A, Feigl AB, Kakuma R, Karam N, Kennedy E, Khoja TA, Maalouf F, Obermeyer CM, Mattoo A, McGovern T, Memish ZA, Mensah GA, Patel V, Petroni S, Reavley N, Zertuche DR, Saeedi M, Santelli J, Sawyer SM, Ssewamala F, Taiwo K, Tantawy M, Viner RM, Waldfogel J, Zuñiga MP, Naghavi M, Wang H, Vos T, Lopez AD, Al Rabeeah AA, Patton GC, Murray CJ (2016) Global burden of diseases, injuries, and risk factors for young people's health during 19902013: a systematic analysis for the Global Burden of Disease Study 2013. Lancet 387(10036):2383-2401. https://doi.org/10.1016/S0140-6736(16)006486

36. Maslach C, Leiter MP (2016) Understanding the burnout experience: recent research and its implications for psychiatry. World Psychiatry 15(2):103-111. https://doi.org/10.1002/wps.20311

37. Reznik A, Isralowitz R, Gritsenko V, Khalepo O, Yu K (2018) Russian Federation university student alcohol use: Smolensk City-a case example. J Ethn Subst Abus 18(4):549-557. https://doi.org/10.1080/15332640.2017.141 7188

38. Peltzer K, Pengpid S (2016) Heavy drinking and social and health factors in University students from 24 low, middle income and emerging economy countries. Community Ment Health J 52(2):239-244. https://doi.org/10.1007/ s10597-015-9925-X

39. Radaev V, Roshchina Y (2019) Young cohorts of Russians drink less: ageperiod-cohort modelling of alcohol use prevalence 1994-2016. Addiction 114(5):823-835. https://doi.org/10.1111/add.14535

40. Gritsenko V, Skugarevsky O, Konstantinov V, Khamenka N, Marinova T, Reznik A, Isralowitz R (2020) COVID 19 fear, stress, anxiety, and substance use among Russian and Belarusian University students. International Journal of Mental Health and Addiction, 1-7. Advance online publication. https:// doi.org/10.1007/s11469-020-00330-z

41. Sorokin M, Kasyanov E, Rukavishnikov G, Makarevich O, Neznanov N, Lutova N, Mazo G (2020) Structure of anxiety associated with the COVID-19 pandemic in the Russian-speaking sample: results from on-line survey. Bull Russ State Med Univ 3:70-76. https://doi.org/10.24075/vrgmu.2020.030

\section{Publisher's Note}

Springer Nature remains neutral with regard to jurisdictional claims in published maps and institutional affiliations.

\section{Submit your manuscript to a SpringerOpen ${ }^{\circ}$ journal and benefit from:}

- Convenient online submission

- Rigorous peer review

- Open access: articles freely available online

High visibility within the field

- Retaining the copyright to your article

Submit your next manuscript at $\boldsymbol{\nabla}$ springeropen.com 